\title{
A Study on Selected Aspects of the Quality of Life of People in Remission after Cancer Treatment with the use of the Individual in-depth Interview Technique
}

\section{H. Kaducakova (Helena Kaducakova)로 G. Nowak (Gabriela Nowak)², L. Suchocka (Lilia Suchocka)3, A. Gozdzialska (Anna Gozdzialska)², M. Pasek (Malgorzata Pasek)4}

${ }^{1}$ Catholic University in Ruzomberok, Faculty of Health, Department of Nursing, SK.

2 Andrzej Frycz Modrzewski Krakow University, PL.

3 The Jan Kochanowski University in Kielce, PL.

${ }^{4}$ Institute of Health, Sciences State Higher Vocational School, Tarnow, PL.

\section{E-mail address:}

helena.kaducakova@ku.sk

\section{Reprint address:}

Helena Kaducakova

Catholic University in Ruzomberok

Namestie A. Hlinku 48

Slovakia

Source: Clinical Social Work and Health Intervention

Volume: 12

Issue: 4

Pages: $31-40$

Cited references: 7

\section{Reviewers:}

Gabriela Lezcano

University of California, San Francisco, USA

Roberto Cauda

Institute of Infectious Diseases, Catholic University of the Sacred Heart, Rome, IT

\section{Keywords:}

Oncology Treatment. Remission. A Qualitative Study. Cancer.

\section{Publisher:}

International Society of Applied Preventive Medicine i-gap

CSWHI 2021; 12(4): 31 - 40; DOI: 10.22359/cswhi_12_4_04 CC Clinical Social Work and Health Intervention

\section{Abstract:}

Background: A characteristic feature of cancer is, among other things, that even after successful oncological treatment, the patient cannot close this chapter of life and the experience of being a cancer patient. In oncology there is no unambiguous definition of a patient as a healthy person.

Methods: The study covered a group of 20 people. In the conducted tests the diagnostic survey method was introduced. The technique of individual in-depth interviews was used. The respondent could fully express his or her own feelings, emotions, thoughts and experiences. 
Results. The respondents stated that positive emotions appeared with the completion of treatment, but indicated that the feelings were not related to the sense of healing but only to the completion of tiring therapeutic procedures. Some respondents complained about the feeling of chronic fatigue. Fatigue was not only related to the physical sphere, although everyone confirmed that the side effects of the therapy persisted for some time. The respondents paid more attention to mental fatigue, which had various forms, e.g.: anxiety about possible relapse; functional losses; feeling of loss caused by radical treatment. Out of 20 respondents, 4 persons indicated a loss of health, especially the sense of joy and happiness, self-esteem, self-confidence, social contacts, family and time.

Conclusions: The research group consisted of 20 respondents, which limits the possibility of formulating generalized conclusions, but indicates various directions of possible improvement and, most importantly, shows how the thinking about cancer can be changed.

\section{Background}

A characteristic feature of cancer is, among other things, that even after successful oncological treatment, the patient cannot close this chapter of life and the experience of being a cancer patient. In oncology there is no unambiguous definition of a patient as a healthy person. The definition of a patient cured from a cancer completely, if they feel healthy for five years after the treatment, is no longer in use. Studies indicate that relapse of the disease may occur even after many years of treatment.

A person in remission faces a big dilemma. On the one hand, joy should prevail, but on the other hand, there is the awareness of the presence of cancer, that will stay for a very long time. This raises a question of how to help the patient to live a happy life despite experiencing the disease [1]. Life after the end of cancer therapy changes because it revaluates the perception of all aspects of bio-psycho-specialist functioning. A person can continue to have health problems related both to the treatment and the location of the cancer. In particular, health will require care, including regular check-ups, usually accompanied by stress and a sense of fear of a possible relapse [2].

The aim of the present study was to learn about the selected factors determining the quality of life of people after the completed anticancer treatment in the period of remission and to try to specify the guidelines for further care of patients and their families and/or significant persons.

\section{Methods}

In the conducted tests the diagnostic survey method was introduced. The technique of individual in-depth interviews was used. There were individual conversations between the respondent and the investigator, without the presence of third parties, in an atmosphere of confidentiality and understanding. The respondent could fully express his or her own feelings, emotions, thoughts and experiences.

An interview scenario, developed on the basis of standardized research tools for assessing the quality of life of people with diagnosed cancer, was applied as a tool. It had an established scheme, but sometimes for the sake of full clarity, auxiliary questions were introduced. The first part of the questionnaire concentrates on sociodemographic issues: age; education; occupation; family situation; information about the respondent's disease unit; type of treatment applied. The second part concerned psychosocial problems, feelings and emotions of the respondent at different stages of the disease starting from the moment of diagnosis, through the period of treatment to the present day. The third part focused on the physical and intellectual spheres.

The study was carried out after receiving 
Table 1 Clinical characteristics of the study group

\begin{tabular}{|lllll|}
\hline P1 & F & 34 & Breast cancer & Surgery Chemotherapy \\
\hline P2 & F & 31 & Bone-based carcinoma & Surgery Chemotherapy \\
\hline P3 & F & 38 & Spinal cord lining & Surgery Radiotherapy \\
\hline P4 & F & 30 & Ovarian cancer & Surgery Chemotherapy \\
\hline P5 & F & 42 & Cervical Cancer & Surgery Radiochemical Therapy \\
\hline P6 & F & 43 & Breast cancer & Surgery Chemotherapy \\
\hline P7 & F & 26 & Hodgkin's lymphoma & Chemotherapy Radiotherapy \\
\hline P8 & F & 35 & Breast cancer & Surgery Chemotherapy Radiotherapy \\
\hline P9 & F & 22 & Hodgkin's lymphoma & Chemotherapy \\
\hline P10 & F & 25 & Ewig's sarcoma & Chemotherapy Radiotherapy \\
\hline P11 & F & 23 & Hodgkin's lymphoma & Chemotherapy Radiotherapy \\
\hline P12 & F & 39 & Ovarian cancer & Surgery Chemotherapy \\
\hline P13 & F & 37 & Breast cancer & Surgery Chemotherapy Radiotherapy \\
& & & & Hormonetherapy \\
\hline P14 & F & 43 & Breast cancer & Surgery Radiotherapy Chemotherapy \\
\hline P15 & M & 34 & Fibre star & Surgery Radiotherapy (Gamma Knife) \\
\hline P16 & M & 41 & Thyroid cancer & Surgery Radiodem treatment \\
\hline P17 & M & 36 & Testicular cancer (Semen) & Surgery Radiotherapy \\
\hline P18 & M & 28 & Nucleus cancer (Nematode) & Surgery Chemotherapy \\
\hline P19 & M & 48 & Scuttlefish & Surgery Chemotherapy \\
\hline P20 & M & 29 & Brain lining & Surgery Radiotherapy \\
\hline & & & & \\
\hline
\end{tabular}

a positive opinion from the Bioethics Committee (No. KBKA/28/O/2015, on 14.05.2015). Respondents came from the vicinity of Krakow in Poland; participation in the study was voluntary; the principle of confidentiality was maintained. The meetings lasted more than 2.5 hours, but some of the respondents were met twice because of too much mental strain caused by one, long meeting or because they chose so.

The study covered a group of 20 people, 14 women and 6 men, reporting to the Primary Care Clinic. The criteria for inclusion in the study are as follows: patients with past cancer; patients who completed cancer treatment in the remission phase of the disease; patients who have undergone cancer treatment in the last 5 years and are currently in the remission phase.

The characteristics of the examined group of patients as follows: the respondents were 22 to 48 years old; 6 of the examined women were married, 2 in separation. The remaining 8 respondents were unmarried, of which 5 had never been married and 3 women divorced during the illness. In the group of the examined men, 5 were married, 1 was a widower. 12 respondents had offspring. As for the education in the group: there were 9 people with higher education; 6 with secondary education; 5 with vocational education. At the time of the research: 4 were studying in different schools ( 3 of them working at the same time); 11 people were working professionally; 6 people were not working (including 1 student); 3 people lived on a pension. Clinical characteristics of the respondents are presented in Table 1.

\section{Results}

The respondents stated that positive emotions appeared with the completion of treatment, but indicated that the feelings were not related to the sense of healing but only to the completion of tiring therapeutic procedures. They were not happy about ,winning the battle for life“. During the interviews, the questions were asked: „How do you see yourself nowadays? Do you think of yourself 
as a fully healthy person?" Only two men felt this way while the others talked about the current stage - the remission of the disease - and did not see it as the end of therapy or a complete cure of the cancer. Moreover, the emotions connected with the end of the therapy were described as a feeling of some kind of loss of security, care and even a loss of life role they had already got used to.

Some respondents complained about the feeling of chronic fatigue. Fatigue was not only related to the physical sphere, although everyone confirmed that the side effects of the therapy persisted for some time. Respondents paid more attention to mental fatigue which had various forms, e.g.: anxiety about possible relapse; functional losses; feeling of loss caused by radical treatment. Respondents also described their outbursts of irritation, anger and frustration. Most of the respondents spoke about the intensification of negative emotions just after finishing the treatment. Some considered this time to be more burdensome than even the time when they were undergoing treatment.

„Of course, at first I was happy to start living a normal life. But what does „normal“ mean? The effects of the treatment were lasting for a long time. I was depressed, I had trouble concentrating and remembering, which again frustrated me, so I burst into anger and fury. I wasn't fit for work, because I was feeling tired all the time. Okay, the cancer is gone but I still feel like a wreck sometimes, and it's been already 2 years “. P15

Negative feelings did not appear immediately after the therapy. It was difficult for patients to understand these emotions: 7 benefited from help of a psychologist; 3 were treated by a psychiatrist due to anxiety disorders and depression. Our own research shows that mental and emotional disorders intensified within about a half to one year after end of treatment. Most of respondents stated that the feeling of being in the doldrums occurred at the time when the positive emotions connected with the end of the treatment were fading away. The period immediately after the end of the therapy was usually described positively, as patients felt joy, relief and sometimes euphoria. However, when asked about the reason for these feelings, only two people replied that they were happy because they were already healthy. The others felt relieved and happy about the end of the tiring treatment. Research has shown that the most intense mental problems were described by people whose treatment was long lasting, preceded by a crippling operation. Those people did not receive or rarely received psychological or psychiatric assistance.

The study showed that 5 of the 6 men and 5 of the women surveyed said they were enjoying life and no longer thinking about the disease. The women felt supported by relatives and friends. Many of the people surveyed did not have full families, or their marriages broke up during the time of illness.

Below, there are excerpts from conversations with 3 patients: 2 treated by a psychiatrist; 1 in care of a psychologist.

„The end of treatment was a moment of joy for me. I was bursting with energy and I was glad I wouldn't have to be bothered anymore. Although the effects of the treatment were slowly subsiding, the disease took away something more important than 2 years of my life, loss of hair, nails, breast or teeth. It took away my joy of life. I started to notice it when the euphoria I felt when the doctor said the illness was over. My family can't understand it: 'You are healthy - why are you not happy?' Many people probably think the same way: We should jump with joy, enjoy the smallest things and the sky should be more blue for us. Meanwhile, I've been treating my depression for several months. My husband, who used to be the funniest guy in the world for me, can't make me laugh anymore. And as I used to live from chemo to chemo, I live from check-up to check-up now. And the sky is the same as it was. The miraculous redefinition of life did not occur to me".P1

„Everyone thought, and so did I, that when the treatment was over, life would be like it was before. Despite the fact that my family and friends quickly forgot about my illness and everything came back to normal for them, unfortunately for me it did not. I am no longer the same person, I can't be happy and I can rarely laugh happily. I used to be a cheerful girl, I was all over the place. Unfortunately, when you leave the hospital, you are happy that it is over, that you can come back to life shyly, in small steps. And then comes the time of check-ups and everything is there again; memories come back; you want to 
vomit when you enter the parking lot. A thousand thoughts per minute. And that is the end of my joy. How am I supposed to feel healthy if I can't forget my condition? It's impossible to forget that there is a hidden cancer inside you and if just one cell ,goes crazy“ - as my doctor said... I can't stop thinking about it." $\mathrm{P9}$

„A few months after the treatment, something happened to me. I was looking for symptoms of the disease all the time and with every smallest change I went to the doctor. At my clinic they think I'm crazy. But when the treatment was over, I felt like someone threw me out of my home. During that year of treatment I attached myself to the hospital, I became a part of it. I received care and support there, sometimes it was better and sometimes worse, but the most important was that my cancer was monitored and dealt with there . And suddenly, what? The end? The worst thing is that the cancer hasn't disappeared completely, although all the time I believed that when treatment ends, you are healthy. But the doctor put me right, even though I would rather not hear that. He said that there were residual lesions which we would have to watch at check-ups, but there would be no more treatment possible. I thought I would be fine after all this year of treatment. When it became clear it didn't work that way, I went crazy. Even at the beginning, when I was diagnosed for the first time, it wasn't as bad as when I realized that I could go through it again. I was slowly falling into... I don't really know into what... I went to a psychologist who sent me to a psychiatrist and he said I had an anxiety disorder. It's better now, but it was really bad. I practically didn't sleep and I kept thinking about a relapse all the time. My heart was throbbing and I was constantly thinking about dying, not only my own Heath but also my loved ones. I sensed danger from all directions. " $P 7$

\section{Sense of loss due to the occurrence of disease.}

Out of 20 respondents, 4 persons indicated a loss of health, especially the sense of joy and happiness, self-esteem, self-confidence, social contacts, family and time.

„Before my illness, I was a completely different person; I was a party boy; it was difficult for me to sit still. The illness made me a bore. Now, after work, I prefer to stay in my room and read a book or watch something. I shut myself away.
I don't have the energy to attend parties, which obviously makes my wife happy. I don't know why it is like that, but a lot of things I used to be happy about, stopped interesting me now. I used to like being the center of attention, I had a lot of friends, now I don't even want to talk to them " P2O

"I've become so gloomy and withdrawn. I used to laugh a lot, now it's really hard to make me laugh. Besides, when I was sick, I didn't feel like seeing anyone or going out, so... when my therapy was over, no one gave me a ring, my phone was silent, and remains silent.. Now, the thought of contacting anybody after such a long time is really embarrassing for me ". $P 8$

„Sometimes I think I won't be alive for long since I've been through this treatment. I know what may happen after this kind of therapy. My aunt was also sick when she was young, she died of a heart attack at 55. I know I have a genetic predisposition. I already have heart problems. I feel sorry for myself and I am overwhelmed with bitterness that I had to get sick. I feel worse than any other people of my age " $P 9$

„The illness took away my health, but also the time when I could have had fun instead of getting sick. I think that what I feel most sorry for are the wasted 2 years of my life. "P11

In addition to the losses associated with the disease and oncological treatment, the subjects indicated positive aspects of the illness. Most often they were related to the changes of their lifestyles, focusing on their own dreams; tightening and strengthening family ties; etc.

"I didn't take care of myself before. Because of my illness: I gave up smoking; I took up exercising; I started to sleep normally; I finally live like a human being. I gave up extra work and spend more time with my family. "P15

„I've always had a 1,000 ideas and plans, but I never realized them. When I pulled myself together after the treatment, I decided that it was time for changes; life is short and there may be no time at all. Before, I did not like to spend money on holidays, not now. I go to a Dance school' I jumped with a parachute; I plan to do all the things I've always wanted to do. When I got sick, I received a signal that I can't just stand still and live life half-heartedly. I take more care of myself than before, and I noticed that my husband takes more care of me than before. I also 
try to help women who go through the same experiences as me. At least this is the best I can do". P5

\section{The sense of loss related to the course of oncological treatment.}

Symptoms occurring during the course of anticancer treatment, sometimes despite their remission, in some people still cause great trauma. This may contribute to mental disorders.

„When my colleague came out of the bathroom and I saw what remind of her hair, I was speechless; her hair came off her head in the shower! We were treated for the same problem; we had the same chemotherapy; only she had already been halfway through her therapy. Then I realized I was going to look like her. And in a month I looked the same. I didn't want to see myself in the mirror, I was disgusting. I could not get over the loss of hair and it was the most awful experience for me. I hardly ever left home then though before, when I still had my hair. Even chemotherapy didn't stop me from going out to a pub with my friends. " $P 9$

„I was most concerned about my appearance. Ifelt ugly, fat, just disgusting. I was jealous of my friends when they came to visit me, I was angry that I looked like this. I swelled up on steroids. My toenails and hair fell off. The hair was the worst.It was thinning out, it was just everywhere, on cushions, on the floor, on clothes, I even had it on my plate when I ate. My hair was like leaves falling down from the tree in autumn and every time it reminded me of my illness. Eventually, there was just a few ridiculous hairs left so my Mom took a razor and shaved them off. We were both howling doing it." P11

The feeling of loss related to chemotherapy and radiotherapy was about hair loss, nails, skin elasticity, vitality. Usually, emotions accompanying these losses are sadness and depression, regret, anger, frustration, jealousy, shame. Men did not pay much attention to appearance.

Surgical treatment can be associated with mutilation, is irreversible and has a huge psychological impact, which was confirmed by respondents. The interviews were difficult, bringing tears and bitterness in many cases, but there were also those who even made jokes about the loss suffered. Men undergoing an orchidectomy did not consider it as a loss that would cause the in- tensification of negative emotions, but rather did not pay attention to it.

„(...) I was thinking about losing my breast: What I'm going to look like? What is my husband going to say when he sees me after the surgery? In fact, I haven't come to terms with the fact that I don't have my breast because whenever I see these disgusting scars and when I sometimes touch this place, I cry straight away. I know I had to do it, but it's hard to accept it. I've been through hair loss, too, but it's grown back now, But my breast hasn't. The Amazons encouraged me to do the reconstruction, but I don't want another surgery, I prefer not to touch this place at all." P13

„Losing your breasts is like losing being a woman. You know, I would have let the doctors cut them both off because I wanted to live but they have always been the symbol of my femininity for my husband. He said at the beginning that the surgery would not change anything. When I was sick I lived with an illness, but after the treatment you come back home, where your husband wants to hug you and suddenly you realize that you don't have breasts; you won't be able to undress because you are ashamed. I have felt like that for a very long time; you can say that we are separated by my disease(...). I go to a psychologist, but I don't think I can ever accept it for the rest of my life. The worst thing is that it still reminds me of the sickness " $P 8$

„Before the surgery, I was still hoping, praying that they wouldn't remove everything from me. But it didn't work; prayers didn't work; I became a 30 year-old woman with menopause; without the possibility of giving birth to a child; a defective one, I'm not fit for anything. I was a strong believer, now I don't believe in anything, I even sang in a Schola. But when God decided that I don't deserve to be a mother, I don't believe in him either (...) I was busy with my career, studies, work... I didn't think of children, after all, I could give birth to them later, I thought I had time, and here there was no time. I recently met a cleric from the Schola. He was very comforting, I mean, he wanted to, but it didn't do any good. When he said that faith works wonders, it made me furious. No faith can make my uterus grow back. The cancer took literally everything from me. " $P 4$

„I had broken bones and had to have my leg 
amputated. When I was lying on the operating table, I thought I didn't want to wake up at all, that I didn't want to live without my leg. I really didn't want to live then. For 6 months after the surgery I had phantom pains, I wanted to kill myself. I suffered from depression and I was being treated for it for some time. I didn't want to talk to anyone, not even to my child. And then it started, rehabilitation and a long way to where I am now. I can walk, my whole family and friends are collecting money for my new superleg. I've learned to live with it, but sometimes I have days when everything annoys and upsets me. Sometimes, I take it out on my family. Even recently I had a situation when I woke up and saw my little son playing with my prosthesis. I got mad and started screaming „Give me that leg back!" When I realized what I was saying, I cried out of laughter. Cancer may have taken my leg but it didn't take away my sense of humor..." P2

\section{Family support, intimate relationships. Relationships in marriages and families are presented below.}

„You know what it's like when a guy is sickit is just unbearable. I feel sorry for my wife for these few months. But I love her even more. If it wasn't for her, I don't know how I would have handled it. She is my private angel. I guess the kids could feel something was wrong, too, because when they saw my head bandaged, I guess I never got so many kisses from my daughter. She was very worried about me. After the surgery and the irradiation I had memory problems for some time, I couldn't recover, the whole family was helping me in this, we all became very close because of my illness " P15

„Before that, we lived just ordinary, everyday life with my wife. When I got sick, I appreciated having her. I' $m$ very grateful for everything. Only because of her I could feel good. I know how deeply she was affected by my illness. The baby / she is on maternity leave / and me - in hospital. But I believe that because of this little toddler everything went so fast, I didn't think about the disease, I just had to get back to life as soon as possible" $P 18$

„(...) I have the greatest family in the world, even though my son sometimes plays with my prosthesis or tells his friends that his mother is a robot. These moments of horror that we all ex- perienced together; this pain and suffering that my family shared with me, all these moments brought us together so strongly. I have the most wonderful husband under the sun. If it wasn't for him, I don't know how it would have ended. Throughout the whole time of rehabilitation he cheered me up, motivated and encouraged me. If it wasn't for him, I wouldn't be able to walk so beautifully now. I don't know if I would manage to pull myself together at all. Recently, we have danced for the first time since then. Family is the most important aspect of all this. It must be terrible not to have support from the family. " $P 2$

Among the spouses, the men were more often talking about hiding their bad moods or ailments because they did not want to show their wives their weaknesses. On the other hand, the female patients usually hid their emotions and problems from their children, for the sake of their wellbeing. Some women have received and continue receiving support from their spouses, but other problems have arisen that make the spouses move away from each other.

As the results of the research presented earlier show, many patients experience psychological problems like anxiety disorders and depression after oncological treatment. Some of them benefit from psychological support, but the majority of the respondents do not want to get help despite their poor psychological condition in the belief that this must be the case that it is a normal phenomenon. A few people also pointed out that they might consider getting psychological support, but they are afraid of being labelled crazy. In Poland, the use of psychological and psychiatric support is still stigmatized. The women surveyed who experience such emotions, are not able to build proper family relations. They often mention conflicts escalating due to their partners' misunderstanding of their deeds, as they change during the treatment and after the therapy. These, in turn, cause increasing tension and often lead one of the parties to step back, to separate or even divorce.

In conversations with women about the problems of family functioning, they admit that they do not cope with emotions even though they know about them. The most frequently mentioned here were: outbursts of anger and irritation; oversensitivity; unjustified claims; rejection of closeness of the partner. The respondents often 
said that these situations were caused by the lack of understanding on the part of the partner.

An important aspect of everyday life is the sexual sphere, especially for the women who underwent mutilating treatments. Some of them are able to cope with this situation others tend to avoid any physical nearness. Their partners cannot understand it, feeling rejected and unfulfilled, which can result in outbursts of anger and resentment towards the women. Respondents often mentioned that their spouses blame them for their rejection or lack of interest.

„....at first my husband and children supported me very much in my illness. I am very grateful to them for that, $X$ would buy me flowers and tell me every day that he would love me the same way without my breasts; the children would give me handmade cards. I also received support from my parents, especially from my mother, who took care of my children, cooked, cleaned and helped me a lot when I had no strength. Despite her help, I wasn't doing well on my own and I'm still not doing well. The medicines helped me a little, but it's still bad. I don't know how X will bear it, our marriage will probably fall apart. I can see he's tired of me, there's practically no sex, and when it happens, it's only in the dark so that I don't show these hideous scars. He's going to leave me, and I admire him for being able to hold out for so long anyway. P8

„My marriage is practically gone. He is young. He will want children and I can't give them to him. That is why I decided I want a divorce. Not because I stopped loving him, but because I'm not the woman he married. I don't want to waste anybody's life". P4

„He left me with my cancer and a small child in my arms. He did it overnight, saying that he did not want to be troubled by me. Obviously he didn't want to, he couldn't even look at me without my breasts. But it was a good thing that he did, because otherwise I would live in this hypocrisy, don't know for how long. "P14.

„....and he left me anyway, because I couldn't force myself to get undressed in front of him. It's pathetic. For 7 years of our marriage, I thought I had the best husband in the world... until I got ill. He kept pushing me to have sex. Sex was the main theme of every single day, but I just didn't want it, I wasn't ready for it. At first I even tried, against my will, as long as he would leave me alone, but afterwards I felt terrible, I just hated him." P13

„At first, there was no intimate life at all. I was depressed after amputation. I didn't even want to think about sex. It took me a long time to get over it and not to be ashamed to show my stump, to take my clothes off. I was afraid that he wouldn't accept it. But he behaved as if nothing had changed, he didn't pay any attention to it at all. He never made me feel that he didn't like me. Now I can even have a laugh about it, I just take off my artificial limb and we're done. " P2

Research shows that the changes in intimate life were caused by both the occurring depression and anxiety disorders, as well as total atrophy of libido. Female respondents indicated shame of getting undressed; loss of sense of sexual attractiveness; fear of pain (after gynecological procedures). Additionally, there were concerns about the inability to have sex; to plan and give birth to a child. The interviewed also raised the problem of doctors skipping the problems of intimacy and sexuality. The lack of sex and the resulting conflicts became the main reasons for the break-up of 3 marriages; 2 out of 3 divorced women were left during the period of treatment. The women who stated that they are now in separation seem to consider the termination of the marriage in the near future. Men were not very eager to talk about their sexuality, the answers were usually very casual and vague and most of them did not talk about any problems. They were unlikely to have had sexual intercourse during the time of illness, but this was not a reason for growing conflicts. As mentioned in the previous interviews with the respondents, it can be concluded that during their illness men received more support from their wives than women from their husbands.

\section{Discussion}

Thanks to early diagnosis, personalized treatment and the use of modern technologies, cancer has now changed its status from incurable to treatable or chronic. Medical personnel, using military language fight against the disease and against the complications of treatment and are focused on the „here and now“ during oncological therapy trying to guarantee the patient the best quality of life at the time of anticancer therapy. The most important goal in many such situations 
is to survive. The fight is to be won. The cancer is to be defeated. How will this process affect patient's life after the treatment is completed? Sometimes this question is not really taken into account. Cancer is such a strong condition that positive emotions can be hard to identify. Uncertainty about the prognosis is evident despite, for example, good epidemiological data on the survivability of people with a particular location of the cancerous lesion and the diagnosed stage of the disease and prognosis.

Recognizing the risks associated with past cancer, EORTC already organized a conference in 2012 at which specialists from various disciplines, eg. clinicians, researchers, social workers, financiers, politicians and patients, discussed the research and health cooperation in the field of cancer survivorship and positive effects of more successful cancer treatment [3].

After completing oncological therapy, convalescents can and will struggle with the late complications of anticancer treatment. Some respondents assumed that a positive end of the treatment was a natural return to so-called ,normality"; to pre-illness functioning. In the survey, the respondents specified that the termination of treatment was associated with the completion of tiring procedures; not with joy or relief from the fact of cure. What is more, respondents reported a loss of sense of security connected with the loss of their social role of being the ,patient“. Then they were the subject of all activities, most probably feeling settled and confident, able to move safely in their ,patient's“ world; although that world offered them a sense of lingering doubt and horror.

Medical personnel are not properly prepared to deal with convalescents. In their study, Lester et al. indicate that oncology nurses did not have sufficient knowledge of planning the survivorship care [4]. There is a need for education. In Poland, this aspect still requires further clarification of approaches in cooperation with nurses of various specialties who the patients and their families may contact at various stages of their lives. That need is also confirmed by the fact that most respondents have not yet come to terms with the changes caused by the mutilating surgical procedure. There is interrelation between the young age and mental and adaptive difficulties. There are no comprehensive proposals for the pa- tient and their loved ones, which could aim to prepare them for life after the treatment $[5,6]$.

Cognitive-behavioral therapy may become an essential part of the patient's treatment, still during illness. Working with beliefs, healthy semantics, and above all acquiring skills to establish a recovery plan and specific tasks for specific time spans, can help significantly in the posttreatment phase. This therapy does not let you lose as a happy life, even if ending with untimely death is also a win [7]. Both, the support of the family and the support of the therapeutic team have a positive impact on shaping active strategies that will help cope with cancer. The most expected type of support in the conducted research is emotional support. What patients await from the members of the therapeutic team, is informational (85\% of respondents) and psychological support $(45 \%$ of the respondents clearly expressed their desire for permanent psychological care).

\section{Conclusions}

Such qualitative research, thanks to its methodology, allows for a deeper analysis of health situations and also for direct identification of the needs, problems and opinions of the patients after the completion of oncological treatment. The research group consisted of 20 respondents which limits the possibility of formulating generalized conclusions, but indicates various directions of possible improvement and, most importantly, shows how thinking about cancer can be changed. The care extended over an oncological patient and their family should be performed not only by specialists in oncology (nurses, doctors, psychologists), but also supported by systemic solutions. It should be multidisciplinary and holistic care at every stage of the healing process.

\section{References}

1. LEPPERT W, FORYCKA M, DE WALDEN K, MAJKOWICZ M (2014) Assessment of the quality of life in cancer patients - recommendations for the staff of oncology and palliative medicine departments. Psychooncology 2014;1: pp.17-29.

2. KOPER A (red.) (2020) Oncological Nursing. Warsaw: Medical Publishing House. PZWL, 2020. 
3. MOSERA EC, MEUNIERB F (2014) Cancer survivorship: A positive side-effect of more successful cancer treatment. EJC Suppl.2014 Jun; 12(1): 1-4. doi: 10.1016/j.ejcsup.2014.03.001

4. LESTER JL, WESSELS AL, JUNG Y (2014) Oncology nurses' knowledge of survivorship care planning: the need for education. Oncol Nurs Forum. 2014 Mar 1;41(2):E35-43. doi: 10.1188/14.ONF.E35-E43.

5. REES S (2018) A qualitative exploration of the meaning of the term ,survivor" to young women living with a history of breast cancer, Eur J Cancer Care (Engl). 2018 May; 27(3): e12847.

6. TRUSSON D, PILNICK A, ROY S (2016) A new normal?: Women's experiences of biographical disruption and liminality following treatment for early stage breast cancer. Soc Sci Med. 2016 Feb;151:121-9. doi: 10.1016/j.socscimed.2016.01.011. Epub 2016 Jan 12.

7. MAULTSBY M C (2013) Rational Behavior Therapy, Publishing house Wulkan, Znin 2013. 